\title{
LAS NUEVAS TECNOLOGÍAS Y EL DOCUMENTAL: RESCATE DE IDENTIDAD Y MEMORIA NACIONAL (Apuntes para una ponencia)
}

\author{
Por Pedro CHASKEL BENKO*
}

1. El cine documental, operando con diferentes tecnologías más o menos sofisticadas ha estado presente desde el nacimiento del cine. No es exagerado afirmar que ha contribuido en forma importante al enriquecimiento de las memoria nacionales.

El camino de estos más de 100 años de desarrollo tecnológico ha estado marcado varios hitos importantes. Este desarrollo estuvo estrechamente ligado -en el caso del cine documental- con la construcción de equipos cada vez más livianos y pequeños y que permitieran la grabación simultánea de imagen y sonido sincronizados.

Lejos están los tiempos de los armatostes (armatostes geniales por lo demás) que acarreaban los camarógrafos de Lumiére, Flaherty o Ziga Vertov. O las cámaras portátiles a cuerda que solo permitían tomas de no más de 20 segundos con las que Joris Ivens hizo sus primeras películas mudas.

Hay que darse cuenta de que el cine sonoro nació en 1929, pero que el sonido para los documentales solo se podía grabar en estudios después de la filmación. Es recién a finales de los años 50 que aparecen las posibilidades de grabar sonido magnético en terreno y algunos años después sonido sincrónico con la cámara... Y luego aparece el video y la digitalización con la posibilidad de grabar imagen y sonido con una perfección creciente.

2. Al mirar al pasado pareciera haber sido casi imposible la realización de documentales y sin embargo ahí están... Y surge la pregunta ¿cual es la importancia real de la sofisticación tecnológica para la realización documental? Por cierto que sería no solo absurdo, sino tonto, negarla. Gracias a los adelantos actuales, la presencia y volumen de los equipos técnicos y humanos se pueden reducir al mínimo y, en consecuencia, su influencia perturbadora en la realidad también ha disminuido en buena medida. Las posibilidades de registrar la vida con espontaneidad aumentan extraordinariamente. El acercamiento a la realidad se hace más viable, menos intrusivo.

3. Pareciera que la tecnología nos está solucionado todos los problemas, incluso ayuda en lo financiero: la obtención de una alta calidad técnica de imagen y sonido cada vez es menos prohibitiva... Y, sin embargo...

\section{¿Qué nos permiten las nuevas tecnologías?}

1. Equipos más livianos y pequeños: Menos intervención

2. Calidad de imagen profesional más barata

\footnotetext{
* Cineasta y profesor del Instituto de la Comunicación e Imagen. Universidad de Chile.
} 


\section{Calidad de sonido profesional más barata}

4. Mayor rapidez y facilidad en el montaje no lineal. Más equipos al alcance individual.

O sea con poco presupuesto y ciertos conocimientos técnicos podemos lograr una imagen y un sonido, cercano sino igual, al nivel profesional (los ingenieros de los canales que arrugaban la nariz ante cualquier obra en Umatic y excomulgaban las en VHS, saltarán de gusto... o se sentirán frustrados).

4. Es, sin duda, la democratización del medio: son muchos, y serán cada vez más, los que ya tienen acceso a la producción de documentales.

Las nuevas tecnologías nos facilitan el acercamiento a la realidad, nos facilitan el descifrar su verdad, nuestra verdad, la mayor o menor verdad que cada uno logre con más o menos esfuerzo, con más o menos conocimientos, con más o menos inteligencia, talento, suerte, sensibilidad, con más... honestidad.

Porque ¡ojo! La democratización del medio no significa que basta con apretar el botón con la cámara en automático, luego ordenar las imágenes en el computador, unirlas por fundidos, ponerle música, un comentario y una buena dosis de efectos y ya está el documental... (si tiene muchas entrevistas mejor, porque hacen mas bulto. Además, dejando hablar a los entrevistados nos ahorramos el locutor, necesitamos menos imágenes, no nos comprometemos y tenemos la posibilidad de hacer hablar a "la ciencia", "el pueblo", "los trabajadores", "los políticos", y muchos otros los y las...).

Pero ¿es eso realmente un documental? Me pregunto cuántos de muchos pretendidos documentales no son más que -en el mejor de los casos- una simple (otras veces no tan simple) acumulación de información.

5. Y como una paradoja adicional estas nuevas tecnologías que nos acercan al registro de la realidad, se niegan a sí mismas... El valor testimonial que antes suponía una imagen ha desaparecido violentamente. Y ello es consecuencia de las posibilidades de alterar, trabajar, cambiar, elaborar, las imágenes, sin evidencia alguna para el espectador. Quiere decir que la verdad de un documental no solo hay que buscarla en sus imágenes, sino también en sus otras características...

Porque ¿basta con "registrar" para tener un documental auténtico? Porque para "registrar" debemos necesariamente situar la cámara y establecer un encuadre. Es decir seleccionamos un algo de la realidad y dejamos al resto de la humanidad y el mundo afuera. Ello implica una decisión: esto sí, aquello no, o sea que el registro deja de ser algo mecánico, nunca es simplemente mecánico porque incluso las cámaras de vigilancia tienen su connotación, obedecen a una intención, representan los intereses de... y dejan de registrar a...

6. En consecuencia al filmar (o grabar), nos guste o no, estamos asumiendo la responsabilidad, no solo de registrar sino de interpretar-para bien o para mal-aspectos del mundo que nos rodea. 
Y esta capacidad de interpretar (y el talento y conocimiento técnico para expresarlo audiovisualmente) depende de la sensibilidad, el esfuerzo, la lucidez, la honestidad y en medida muy importante del conocimiento que de esa realidad tengamos como realizadores.

Cierto, existen los documentales, llamémoslos de descubrimiento, en que el realizador no sabe con lo qué se va a encontrar y junto a su cámara nos descubre una nueva realidad antes desconocida. Pero para ser capaz de descubrir (y esto lo saben bien los científicos) hay que saber leer las señales que nos anuncian o delatan lo desconocido, lo nuevo. Si no, corremos el riesgo de pasar de largo sin darnos cuenta. Es decir, sí necesitamos una base de conocimientos previos que -y no es lo menos importante- nos ayudará a estar en la sintonía necesaria para que nuestra sensibilidad sea capaz de detectar lo esencial de la realidad a la que estamos enfrentados.

De nuestro conocimiento, comprensión, curiosidad, capacidad de asombro ante la realidad, y muchas veces de la valentía y honestidad para asumirla, es que depende la calidad de nuestra interpretación, de la profundidad y riqueza de nuestra "mirada".

7. $\quad \mathrm{Y}$ esto tiene mucho que ver con la búsqueda, rescate y valorización de la o las identidades y la memoria nacional.

En buena medida lo que se llamó "el nuevo cine chileno" de finales de los 60 -con Aldo Francia, Raúl Ruiz, Miguel Littin y Helvio Soto, y ya antes que ellos en el documental Sergio Bravo y quien escribe- surge, entre otras causas, como reacción de la gran mayoría al poco cine que se hacia en Chile en aquel entonces, apoyado por una seudo crítica periodística complaciente, y que poco o nada tenia que ver ni con la realidad ni con la identidad nacional. Peor aún, porque entregaba al espectador una imagen ultraconvencional, falseada, edulcorada, frívola y superficial, de su propia realidad. Y esto vale tanto para películas de ficción de ambiente campesino, urbano, sureño, marino o minero, como para los documentales. (Para ser justos debemos exceptuar las películas de Giorgio di Lauro y Nieves Yankovic, Patricio Kaulen, Naúm Kramarenco, Armando Parot y Fernando Balmaceda).

El rescate y afirmación de una cierta identidad (o identidades) nacional y -en el marco de la expresión artística- la búsqueda y elaboración de formas de expresión propias, ya formaba parte de las inquietudes de nuestro quehacer en los años 60. Por muchos años esta preocupación pareció diluirse. Hoy día, frente al desafío de una globalización que amenaza con arrasar con demasiados cosas nuestras, la inquietud y la preocupación vuelve a manifestarse con fuerza. (Por una vez, bien por la globalización). Fue, es y será tarea de los documentalistas seguir, cada vez más, contribuyendo a profundizar el conocimiento de lo nuestro y la autoconciencia de nuestra identidad, y de esta manera nutrir, enriquecer y actualizar la a veces desmemoriada memoria nacional.

8. En relación a "rescate de identidad", habría que partir por decir "registro de la identidad"... y a propósito del acto de registrar antes habría que plantearse el detectar la tal identidad... y ¿dónde buscarla, dónde detectarla? Obviamente en la realidad que nos rodea, y en buena medida en la historia que nos precede. Y es por aquí por donde podemos encontrarnos con el cine documental y también con las nuevas tecnologías. 
Pero, ¿de qué identidad estamos hablando? ¿es lo mismo la identidad de los pobladores de La Victoria que la de los habitantes de La Dehesa? ¿la de los ingenieros comerciales y la de los pescadores artesanales? ¿la de los profesores primarios de Toltén Bajo y la de los catedráticos de la Universidad Finis Terrae? ¿la de los arrieros y campesinos del Cajón del Maipo y la de los miembros del Estado Mayor del Ejército?... ¿no será más adecuado hablar de identidades, así en plural? No pretendo contestar ahora estas preguntas, simplemente las dejo planteadas... (tal vez algunos recuerden "La gran ilusión" de Jean Renoir que algo sugiere sobre el tema). Y las dejo planteadas dentro del marco que nos interesa aquí, el marco de las nuevas tecnologías y en qué medida su utilización en el documental nos permite acercarnos más a la realidad.

9. Joris Ivens planteaba durante una entrevista una idea que me parece de validez permanente. Decía Ivens, en 1965 (traduzco libremente del inglés):

"Nuestras posibilidades técnicas hoy día han crecido enormemente. Durante los años 30, cuando tratábamos de mostrar la realidad y la verdad, nuestra honestidad e integridad eran idénticas a aquellas de las de los realizadores documentalistas del presente. (...) ahora la técnica, gracias al sonido sincrónico y a las películas de altas sensibilidades que hacen las luces innecesarias, permite aún mayor autenticidad, pero no necesariamente por eso una mayor veracidad del material filmado. Pienso que con un autor responsable la autenticidad del material es solo un elemento de la verdad fundamental de la obra".

\section{Concluyo:}

Ahora aparentemente es más fácil, la tecnología nos ayuda extraordinariamente, pero justamente por eso, por tener tantas posibilidades abiertas, por tener equipos pequeños, por tener cantidades de cinta para casi ilimitadas horas de grabación, porque una toma puede durar más de una hora sin que se nos acabe la película o la cuerda de la cámara, porque tenemos baterías que parecieran no agotarse nunca, por poder grabar con la luz de la luna, por tener micrófonos inalámbricos, etcétera, porque pareciera que las máquinas por sí solas pueden prácticamente realizar nuestras películas y hacerlas aparecer cada vez más creíbles, más verosímiles, por todo eso es que debemos asumir una ética de la responsabilidad frente a nuestro quehacer.

Si consideramos que uno de los objetivos -para mí el principal- de todo auténtico documental, es la búsqueda de la verdad, de la verdad acerca del tema o asunto del documental, toda herramienta que nos ayude a acercarnos a ésta, pues ¡bienvenida sea!

Sin embargo, nunca olvidemos que las nuevas tecnologías solamente nos ayudan en el acercamiento a la realidad, pero que la verdad (las verdades, alguna de ellas o la verdad fundamental como decía Ivens) de esa realidad tenemos que encontrarla, descubrirla, desentrañarla nosotros. Ese es nuestro desafío. 